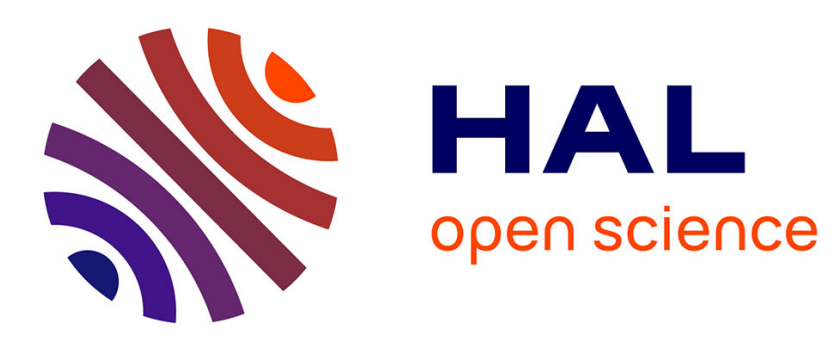

\title{
A pulsed sputter negative ion source
}

R. Balzer, F. Sperisen

\section{To cite this version:}

R. Balzer, F. Sperisen. A pulsed sputter negative ion source. Revue de Physique Appliquée, 1977, 12 (10), pp.1477-1478. 10.1051/rphysap:0197700120100147700 . jpa-00244351

\section{HAL Id: jpa-00244351 https://hal.science/jpa-00244351}

Submitted on 1 Jan 1977

HAL is a multi-disciplinary open access archive for the deposit and dissemination of scientific research documents, whether they are published or not. The documents may come from teaching and research institutions in France or abroad, or from public or private research centers.
L'archive ouverte pluridisciplinaire HAL, est destinée au dépôt et à la diffusion de documents scientifiques de niveau recherche, publiés ou non, émanant des établissements d'enseignement et de recherche français ou étrangers, des laboratoires publics ou privés. 


\title{
A PULSED SPUTTER NEGATIVE ION SOURCE
}

\author{
R. BALZER and F. SPERISEN \\ Laboratorium für Kernphysik, Eidg. Technische Hochschule, \\ 8093 Zürich, Switzerland
}

\begin{abstract}
Résumé. - Une source modulée d'ions de Césium a été construite en vue de son application dans une source à désagrégation de système Hortig.

Un faisceau d'ions de Cs est extrait d'un ionisateur de surface et groupé en impulsions d'une longueur de quelques ns en modulant la vitesse et la base de vol.

Avec ce système, nous espérons produire un intense faisceau modulé d'ions négatif.

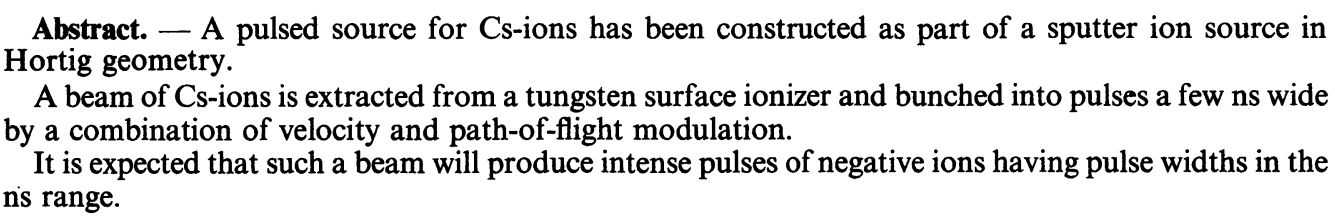

1. Introduction. - Intense pulses of ions in the nanosecond range are usually generated by velocity modulation. Ions of mass $m$, charge $e$ and energy $e U_{\mathrm{o}}$ are accelerated through a gap by applying a modulating voltage $\Delta U(t)$ so that the resulting velocity is given by

$$
v(t)=v_{0}+\Delta v(t)=\frac{v_{0} s}{s-v_{0} t}
$$

where $\quad v_{0}=\sqrt{2 U_{0} \frac{e}{m}}$.

After the drift length $s$, the ions accelerated in the time interval $\mathrm{O} \leqslant t \leqslant t_{1}$ are concentrated in a short bunch having a length which depends on the quality of the original beam.

This principle can also be applied to heavy ions. In the case of sputter-type ion sources it is obvious that only the primary beam of the positive cesium ions should be pulsed so that the sputter target serves as a point source of negative, pulsed ions. Two essentiel advantages have thus been attained : (a) The negative ion beam has no additional energy spread and (b) upon changing from ion species to another, no adjustments have to be made to the pulsing system. Furthermore, the low velocity $v_{0}$ of the Cs-ions allows a short drift length $s$ as well as a high average intensity $I$ of the pulsed beam. Assuming the maximum relative velocity modulation $\left(\Delta v / v_{\mathrm{o}}\right)_{\max }=A$ to be given, it follows from eq. (1) that for a pulse separation $T$, the ratio of the average intensities of the pulsed to unpulsed beam is

$$
\frac{I}{I_{0}}=\frac{s}{v_{0}} \frac{1}{T} \frac{A}{A+1}
$$

However, the low velocity also has the disadvantage that the geometrical length of an $1 \mathrm{~ns}$ ion bunch is only a fraction of a millimeter. Therefore the arrangement of Cs-beam and sputter target should be so chosen that the time of impact of the ion bunch does not increase the pulse width. This condition is more easily fulfilled in a Hortig-geometry source [1] or in a modified inverted sputter source [2] than in one of the Middleton-type [3].

2. Experimental set-up. - On the basis of the considerations outlined above, a pulsed ceasium ion source has been constructed. The parameters were chosen to be : drift length $s=52.5 \mathrm{~cm}$, accelerating potential $U_{\mathrm{o}}=30 \mathrm{kV}$, maximum modulating amplitude $\Delta U\left(t_{1}\right)=10 \mathrm{kV}$. Substituting these values in eqs. (1) and (2) shows that beam lengths of $338 \mathrm{~ns}$ can be bunched into pulses, which, for a repetition rate of $2 \mathrm{MHz}$, corresponds to a duty cycle of 0.67 .

A schematic representation of the source is shown in figure 1. Caesium vapour from the boiler 1 passes through a tungsten surface ionizer 2 ; the ions thus formed are extracted by an acceleration lens 3 and focussed by an einzel lens 4 and an electrostatic steerer 7 onto the center of the sputter target 8 . An organic fluid cooled aperture 5 serves to remove unwanted Csvapour. The entire system 3 to 8 is set at the negative accelerating potential $U_{\mathrm{o}}=-30 \mathrm{kV}$, whereas the extraction system for negative ions 9 lies at ground potential.

The modulating voltage $\Delta U(t)$ is applied to the ionizer 2; the latter, together with the Cs-boiler, is mounted in vacuum and insulated from the rest of the 


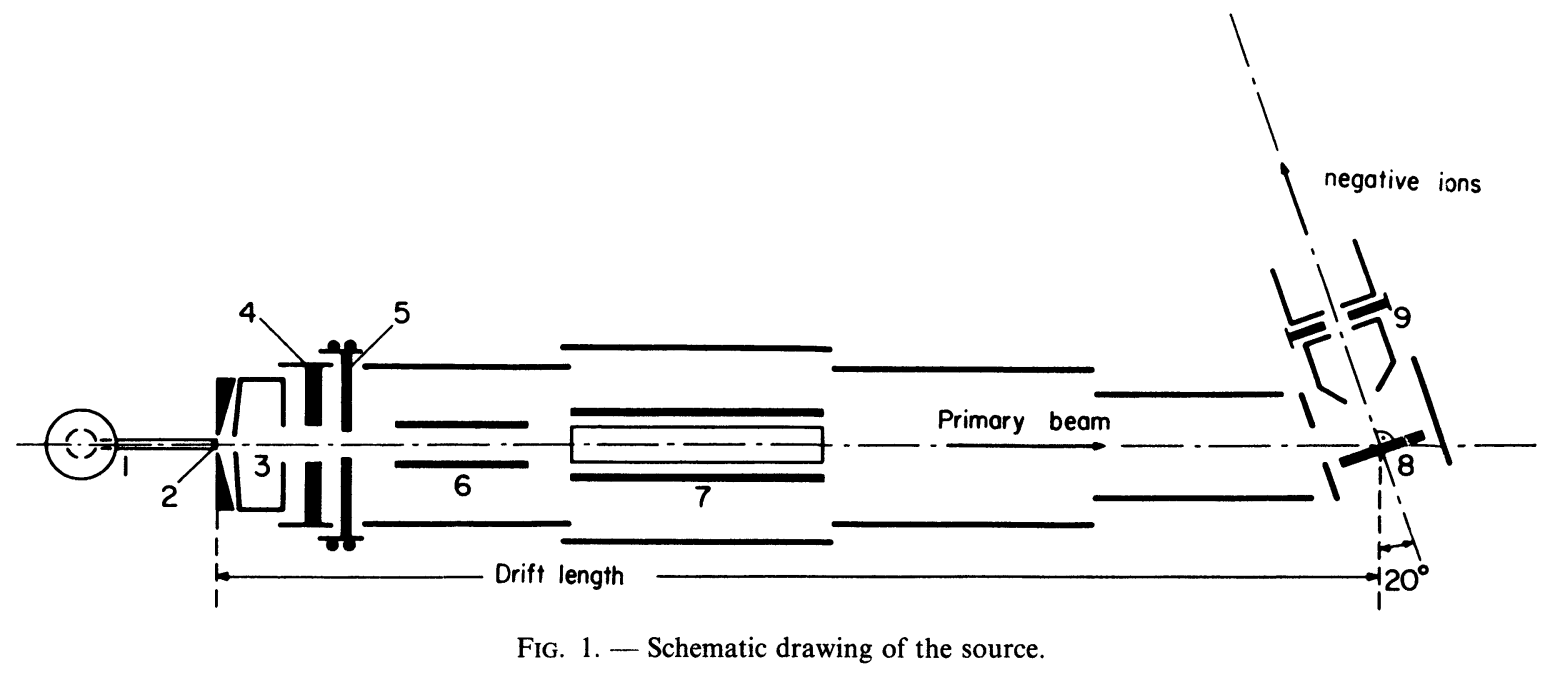

apparatus. The Cs-boiler is heated by thermal radiation, its temperature measured and stabilized by an infrared radiation sensor. The ionizer is heated by electron bombardment, the positive modulating voltage $\Delta U(t)$ being used as the accelerating potential. The heating power thereby depends on the rms-value of $\Delta U(t)$ and has to be brought to the correct setting of typically $70 \mathrm{~W}$ by the electron emission. This procedure is not at all critical, yet, we intend to replace the present electron bombardment heating by an inductive rf-heating system.

The design center value for the pulse length was assumed to be $1 \mathrm{~ns}$, corresponding to a bunching factor of 338. Such a large value can only be attained if the modulating voltage follows the theoretical course

$$
U(t)=U_{0}\left[\left(\frac{t_{0}}{t_{0}-t}\right)^{2}-1\right], t_{0}=\frac{s}{v_{0}}
$$

with a deviation of less than $8 \times 10^{-4}$. To construct a suitable generator for this voltage it is convenient to expand the relation (3) as a series

$\frac{\Delta U(t)}{U_{0}}=2\left(\frac{t}{t_{0}}\right)+3\left(\frac{t}{t_{0}}\right)^{2}+4\left(\frac{t}{t_{0}}\right)^{3}+5\left(\frac{t}{t_{0}}\right)^{4}+\ldots$

Substituting the values $t_{\mathrm{o}}=s / v_{\mathrm{o}}=2.52 \mu \mathrm{s}$ and the maximum value of $t=t_{1}=0.338 \mu \mathrm{s}$, the variable $t / t_{\mathrm{o}}$ is found to be 0.1285 ; therefore, in order to obtain the required accuracy, terms up to the 4 th ordor must be taken into consideration.

The necessity of having a bunching factor of over 300 and the corresponding accuracy in the modulating voltage can be reduced by an order of magnitude by introducing an additional flight path modulation. For this purpose, an extra pair of deflectors 6 (Fig. 1) have been inserted in the beam line; the bunch can thus be tilted with respect to its direction of flight so that its longitudinal axis lies parallel to the sputter target upon impact. If the beam can be focussed into a sufficiently small diameter, the length of the bunch may then amount to a few millimeters.

3. Preliminary results. - The first tests were carried out at an accelerating potential of $15 \mathrm{kV}$ and by using a modulator with a maximum amplitude of $3 \mathrm{kV}$. For the form of the modulating voltage, only terms of the 2nd order of the series (4) were taken into consideration. The observed pulse width was considerably larger than the calculated value and it could be shown that this was mainly due to the differences in the flight path in the einzel lens. At the present time the lens system is to be altered such that the focussing will predominantly be effected by the accelerating lens and the einzel lens will be needed only for minor corrections.

\section{References}

[1] MÜLler M. and Horting G., IEEE NS-16 (1969) 38.

[2] Chapman K. R., IEEE NS-23, 2 (1976) 1109.

[3] Middleton R., IEEE NS-23, 2 (1976) 1098. 